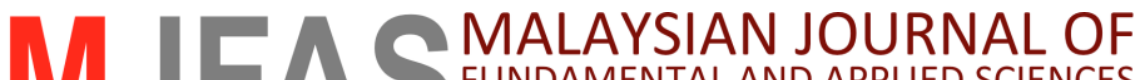

\section{Hydrolysis of microcrystalline cellulose isolated from waste seeds of Leucaena leucocephala for glucose production}

\author{
Maryam Husin a, c,Nurnadiah Rahim b, Mohd Radzi Ahmad b, Ahmad Zafir Romli a, Zul Ilham c," \\ ${ }^{a}$ Faculty of Applied Sciences, Universiti Teknologi MARA, 40450 Shah Alam Selangor, Malaysia \\ b Phytochemistry Program, Natural Products Division, Forest Research Institute Malaysia (FRIM), 52109 Kepong, Selangor, Malaysia \\ Biomass Energy Laboratory, Institute of Biological Sciences, Faculty of Science, University of Malaya, 50603 Kuala Lumpur, Malaysia
}

* Corresponding author: ilham@um.edu.my

\section{Article history}

Received 11 May 2018

Revised 25 July 2018

Accepted 28 August 2018

Published Online 14 April 2019

\begin{abstract}
The waste seeds of Leucaena leucocephala (LLS) used in this study were unused residues obtained after oil and polysaccharides extraction. The microcrystalline cellulose (MCC) was isolated from LLS by acid treatment. MCC produced was, then, further converted to glucose by using sulphuric acid at $121^{\circ} \mathrm{C}$ by varying the acid concentration and reaction time. The sugar composition was analyzed by using the phenol-sulfuric acid method and pre-column derivatization HPLC technique. The yield of glucose ranging from $70-85 \%$ could be obtained from MCC hydrolyzates, depending on the hydrolysis factors, which corresponding to around $57-75 \%$ of the percentage conversion of MCC to glucose. Cellulose isolated from LLS was, therefore, potentially suitable to be utilized in liquid biofuels and other value-added chemicals such as bioethanol, 5-hydroxymethylfurfural(HMF), and levulinic acid.
\end{abstract}

Keywords: Leucaena leucocephala seed, waste residue, micro cellulose, acid hydrolysis, glucose

\section{INTRODUCTION}

Lignocellulose is the key structural element of plants and found in roots, stalks, seeds, and leaves at various compositions. Generally, it is composed of three major components, which are cellulose (38-50\%), lignin (15-30\%), hemicellulose (23-32\%) and a small amount of pectin, protein, extractives, and ash (Kopania et al., 2012). Cellulose is a renewable biopolymer with high potential as a sustainable raw material production for various applications which can be obtained in abundance in nature, relatively cheap and biodegradable (Kalia et al., 2011; Jose et al., 2014; Duff \& Murray, 1996). It is widely used in many aspects and industries, such as food industry, pharmaceutical, paint, polymers, and much more. Cellulose can be found in different parts of the plant such as bast, seed, leaf, straw, grass, and wood. The amount of cellulose in the plant is varied, depending on species, origin, maturity, and extraction process. Therefore, the application of different biomasses used for the preparation of cellulose is expected to give different properties of cellulose such as crystallinity, particle size, molecular weight, degradation temperature and moisture content.

Furthermore, lignocellulosic materials can be converted into sugar alcohol, oxygenated bio-oil, and hydrocarbon by various chemical treatment methods and can be further utilized for production of variety of valuable chemicals such as glucose, sorbitol, and hydroxymethylfurfural (Ghani et al., 2008). Three types of hydrolysis processes are typically used to produce a variety of sugars, which are dilute acid, concentrated acid, and enzymatic hydrolysis. The yield of sugar from hydrolysis of lignocellulosic biomass is depended on the type of biomass due to different cell walls compositions and structures, the type of monosaccharides and lignin presented and the type of bonds between them. Extensive studies have been completed on hydrolyzed cellulose from rice straw, sugarcane bagasse, cotton cellulose and corn stalk (Li et al., 2012; Punsuvon et al., 2008; Yoon et al., 2014; Zhu et al., 2005). Chemical hydrolysis method is the most common method used to break the $\beta-1,4$-glycosidic bonds of the cellulose structure by using different kinds of acids such as $\mathrm{HCl}, \mathrm{H}_{2} \mathrm{SO}_{4}, \mathrm{HF}$ and organic acids (Dusan et al., 2014; Vala \& Tichagwa, 2013). Acid hydrolysis of lignocellulosic materials for glucose conversion has been applied in industrial production for almost a century ago (Lee, 1997; Sun et al., 2015; Szczodrak \& Fiedurek, 1996; Taherzadeh et al.,1997).

Hutomo et al. (2015) compared the cellulose hydrolysis to glucose using two different acids. Based on their study, sulphuric acid gave higher glucose yield compared to hydrochloric acid. In another study, Wijaya et al. (2014) evaluated the effect of crystallinity on cellulose degradation of different categories of biomass (hardwood, softwood, and non-woody biomass). They reported that the lowest crystallinity gave highest glucose yield. Another acid that frequently used for acid hydrolysis is phosphoric acid. Gámez et al. (2006) treated sugarcane bagasse with phosphoric acid in the autoclave at $122^{\circ} \mathrm{C}$, which resulted in the high glucose yield of $6 \%$ at condition of $300 \mathrm{~min}$ and $3.2 \mathrm{~g} / \mathrm{l}$ phosphoric acid. In different study that using the same acid, Orozco et al. (2007) conducted the acid hydrolysis using a microwave reactor. They found that the highest glucose yield was at reaction time between 3-5 min with $7.5 \%$ acid concentration. Lenihan et al. (2010) also treated potato peels with phosphoric acid using a pilot batch reactor. The optimum sugar yield of $82.5 \%$ was obtained at $135^{\circ} \mathrm{C}$ and $10 \%$ (w/w) acid concentration, which $98 \%$ of the total sugar was glucose. Acid hydrolysis can be considered environmentally friendly due to the possible separation of salt and alcohol recovery.

Recently, hydrolysis methods of cellulose to glucose using subcritical, hot compressed water, supercritical, as well as combination of both have been intensively investigated and developed (Bentivoglio et al., 2006; Cardenas-toro et al., 2014; Iryani et al., 2014; Kamio et al., 2008; Phaiboonsilpa et al., 2011). 
The application of ionic liquid as a solvent for cellulose degradation is also gained considerable interest due to high yield of glucose (Hsu et al., 2011; Liu et al., 2017; Morales-delaRosa et al., 2012; Zhuo et al., 2015). Dilute acid hydrolysis is the preferred process due to the absence in requirement of acid recovery, where the ionic liquid is needed and thus, making the ionic liquid application for cellulose hydrolysis becomes expensive (Kumar et al., 2015; Liu et al., 2017; Sun et al., 2013). The enzymatic methods for cellulose degradation have advantages due to selectively to the specific reaction and no formation of by-products, which can disturb the next subsequently process. Conversely, enzymatic hydrolysis of cellulose has been observed to be not practical to industrialize because of the high cost of enzymes and the hydrolysis process that occurred at a slow rate (Sasaki et al., 2012). Combination of acid hydrolysis and enzymatic hydrolysis was applied by Amiri \& Karimi (2013) to enhance cellulose degradation. Initially, cellulose was treated using dilute-acid hydrolysis for glucose production and the residual solid from the acid hydrolysis was enzymatically hydrolyzed. The proposed method successfully produced a high yield of glucose as $95.4 \%$.

Another aspect, extraction of fruit and seed for commercial products such as juice, sauce, ketchup, puree, paste or canned has commonly produced the insoluble residual or waste (Kumar \& Venkatesh, 2014). Sometimes, the amount of residual waste produced is higher than the amount of extract used. The seed of Leucaena leucocephala has been evaluated for biodiesel and pharmaceutical product (Aderibigbe et al. 2011; Hakimi et al., 2017; Nehdi et al., 2014). Depending on the seed, discarding this material can generate an environmental impact not only due to its toxicity such as jatropha (Parawira, 2010) but also due to the high produced volume. It is necessary to propose an adequate use for these cakes/residual, and one of the potential alternatives is to extract the valuable products with high commercial values, such monosaccharides and lignin. Thus, it can maximize the value derived from the biomass feedstock. To the best of our knowledge, there is no known report yet that addressing the utilization of seed residues obtained from industrial extraction for glucose production.

The aim of this work was to produce glucose from the microcrystalline cellulose (MCC) obtained from two types of waste Leucaena leucocephala seeds. The effects of reaction conditions (acid concentration and reaction time) on the sugar yields were investigated, and the hydrolysis products were analyzed by Ultraviolet spectroscopy and High-Performance Liquid Chromatography (HPLC). In addition, MCC samples were characterized using Fourier Transform Infrared (FTIR), X-ray Diffraction (XRD), and Field emission scanning electron microscopy (FESEM).

\section{EXPERIMENTAL}

\section{Materials}

Two types of waste Leucaena leucocephala seeds were obtained from Biomass Energy Lab University Malaya and Forest Research Institute Malaysia (FRIM); seeds after extraction of oil for conversion to biodiesel (OELLS) and waste seed after polysaccharides extraction (PELLS), respectively. Acetic acid, nitric acid, and hydrochloric acid were purchased from Fisher Scientific.

\section{Isolation of microcrystalline cellulose (MCC)}

Extraction with boiling water under reflux was used in order to remove primary and secondary metabolites. The extraction was carried out at $95-100{ }^{\circ} \mathrm{C}$ for $2 \mathrm{hr}$. After filtration, aqueous extract was discarded and the insoluble residues were collected and dried in the oven at $60{ }^{\circ} \mathrm{C}$ before being stored for the isolation of cellulose.

The isolation method was adapted based on original procedures by Sun et al. (2004) with some modifications. The insoluble residue was separated by filtration and thoroughly washed with distilled water. Then, the waste seeds were hydrolyzed with $2.5 \mathrm{M}$ hydrochloric acid under reflux for 1 hour at $90{ }^{\circ} \mathrm{C}-100{ }^{\circ} \mathrm{C}$. The insoluble residue (MCC) was then filtered through cotton cloth and washed repeatedly with distilled water until it was free from acid. The MCC was dried in an oven at $105^{\circ} \mathrm{C}$ and stored in a desiccator until further evaluation would be carried out. The MCC obtained after drying was snowy-white in appearance.

\section{Hydrolysis of MCC to glucose}

In general, $1 \mathrm{~g}$ of MCC was treated with different concentrations of sulphuric acid: $5,10,15,20$, and $15 \%$. The samples were stirred continuously for $1 \mathrm{~h}$ to allow the acid to be absorbed in the MCC. This was followed by slowly adding of distilled water to the reaction mixture in order to decrease the concentration of the $\mathrm{H}_{2} \mathrm{SO}_{4}$ to $2 \mathrm{M}$, before it being autoclaved at $121^{\circ} \mathrm{C}$ for $60 \mathrm{~min}$. After the reaction was completed, the hydrolyzates were cooled and neutralized using $4 \mathrm{M}$ sodium hydroxide until the $\mathrm{pH}$ reached 7.0. Neutralization process caused the formation of the by-product (formation of salt known as sodium sulfate) in the hydrolyzate solution. The hydrolyzate (simple sugar) was separated from the sodium sulfate salt by the addition of mixture consisted of ethanol-distilled water. The salt was filtered and the filtrate containing sugar was dried, weighed and stored in the cold room.

Based on the results of this experiment, one of the tested acid concentration conditions resulting in a higher yield of glucose was selected and used to investigate the effects of hydrolysis conditions by changing the autoclave time. The reaction times tested in this study were $30,60,90$ and $120 \mathrm{~min}$.

\section{Chemical characterization}

The chemical compositions of OELLS and PELLS wastes were determined according to the standards of American Society for Testing and Materials (ASTM) alcohol-toluene solubility (ASTM D 1107-56), holocellulose (ASTM D 1104-56), and lignin (ASTM D 1106-56).

\section{Characterization of MCC}

Fourier transform infrared (FTIR) spectroscopy was used to measure the functional groups presented in the MCC by a Perkin-Elmer Spectrum 100 IR spectrophotometer. The MCC was mixed with potassium bromide $(\mathrm{KBr})$ and compressed into thin tablets. Spectra of all samples were recorded in the range of $4000-450 \mathrm{~cm}^{-1}$ and the total number of scans was 25 .

The crystallinity of the samples was analyzed by using an X-ray diffractometer (X'Pert PRO MD PANalytical) with $\mathrm{CuK} \alpha$ radiation at $35 \mathrm{kV}$ and $30 \mathrm{~mA}$. The X-ray diffraction patterns were recorded at a rate of $1.5^{\circ} \mathrm{min}^{-1}$. The Crystallinity Index has been calculated using the methods as described previously (Adel et al., 2011; Trache et al., 2014; Wang et al., 2010).

Field emission scanning electron microscopy was carried out using a JEOL JSM-7600F. A small amount of the LLS, cellulose and MCC samples were prepared by dispersing dry powder on double-sided conductive adhesive tape. The FESEM micrographs were obtained to study the surface morphology and crystallite size of each sample.

\section{Analysis of sugars}

The dried hydrolyzate product (sugar) was analyzed using UV Visible Spectroscopy and High-Performance Liquid Chromatography (HPLC). These tests were conducted to identify the purity of the isolated materials in terms of the carbohydrate content and monosaccharide compositions, respectively. The total carbohydrate or sugar extracted was estimated spectrophotometrically by hydrolyzing glucose hydrolyzate by phenol-sulfuric acid method (Dubois et al., 1956). In brief, about $100 \mathrm{mg}$ of dried hydrolyzates was dissolved in $100 \mathrm{ml}$ of distilled water. Next, $10 \mathrm{ml}$ of solution was placed into test tubes and $1 \mathrm{ml}$ of $2 \%$ phenol solution was added. Then, $5 \mathrm{ml}$ of concentrated sulphuric acid was added rapidly. The solution was systematically mixed for 30 minutes in an incubating shaker. External calibration glucose standards were performed for the quantification of total carbohydrate contents. The amount of carbohydrate content in cellulose hydrolyzates was determined and then expressed as the percentage of glucose. The samples and standard were then analyzed under UV absorbance at $490 \mathrm{~nm}$ using UV-Vis spectrophotometer in triplicates for each sample.

The analysis of sugars was carried out on a Series LC-10A HPLC system (Shimadzu, Kyoto, Japan) equipped with an aminopropylsilyl column and refractive index detector (RID-10A). The chromatographic 
separation was done using acetonitrile/water, 7:3 (v/v) as a mobile phase at $80{ }^{\circ} \mathrm{C}$ of column temperature. Identification of the components was performed by comparison of retention times with sugar standards.

\section{RESULTS AND DISCUSSION}

\section{Lignocellulose composition}

The images of PELLS and OELSS were shown in Fig. 1. The color of PELLS was dark brown while OELSS was slightly discolored. The dark color might be contributed by the high content of non-cellulosic materials such as lignin and hemicelluloses and this could be confirmed by the chemical composition data (Table 1).

The chemical compositions of both PELLS and OELLS were summarized in Table 1. PELLS and OELLS showed similar holocellulose content that equivalent to other different cellulosic sources such as wood fiber reported by Poletto et al. (2014) and Melon seed shell found by Pius et al. (2014), which was approximately $45 \%$. (a)

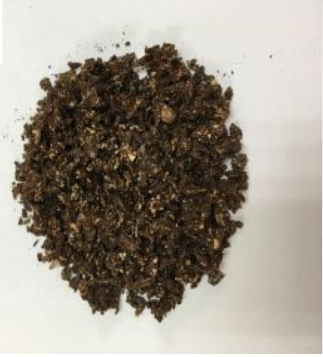

(b)

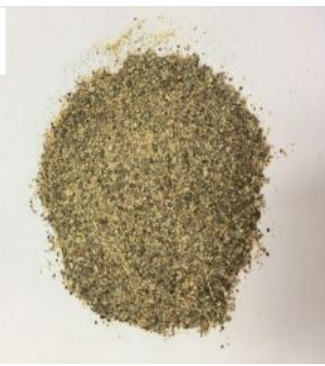

Fig. 1 Images of Leucaena Leucocephala seeds: (a) PELLS and (b) OELLS.

The isolation of cellulose fibers required the removal of other components such as lignin, hemicellulose, and pectin from the biomass. Generally, in this method, a dried biomass was immersed in acids or bases solution under specific temperatures for a period of time. The treated biomass was then filtered to separate the solid substrate from the liquor. Higher lignin removal was necessary to give better cellulose conversion or degradation. Siqueira et al. (2013) studied the effect of lignin composition on the cellulose hydrolysis and it was found that the cellulose conversion was higher when lignin composition was decreased.

Table 1 Chemical composition of Leucaena Leucocephala waste seed.

\begin{tabular}{ccc}
\hline Component & PELLS (wt\%) & OELLS (wt\%) \\
\hline Alcohol toluene solubility & 7.46 & 9.78 \\
Klason lignin & 22.20 & 17.1 \\
Acid soluble lignin & 4.23 & 4.63 \\
Holocellulose & 47.30 & 51.90 \\
\hline
\end{tabular}

The purity of obtained cellulose was depended on the presence of band associated to lignin and hemicellulose. It was determined by comparing the IR spectra for MCC-PELLS and MCC-OELLS as shown in Fig. 2, where no significant difference was observed between these spectra. These results indicated that the obtained cellulose structure was unchanged although the waste seeds were produced from two different processes. A significant reduction in intensity of the peak around $1700 \mathrm{~cm}^{-1}$ was attributed to the $\mathrm{C}=\mathrm{O}$ stretching of the acetyl group and uranic ester groups of the hemicellulose, which was also noticeable for MCC-PELLS. On the other hand, peaks around $1200 \mathrm{~cm}^{-}$ ${ }^{1}$ and $1500 \mathrm{~cm}^{-1}$ which corresponded to the $\mathrm{C}-\mathrm{O}$ stretch and $\mathrm{C}=\mathrm{C}$ bonds in lignin (Mandal \& Chakrabarty, 2011) could not be observed in all spectra, indicating that lignin was removed during the acid hydrolysis.

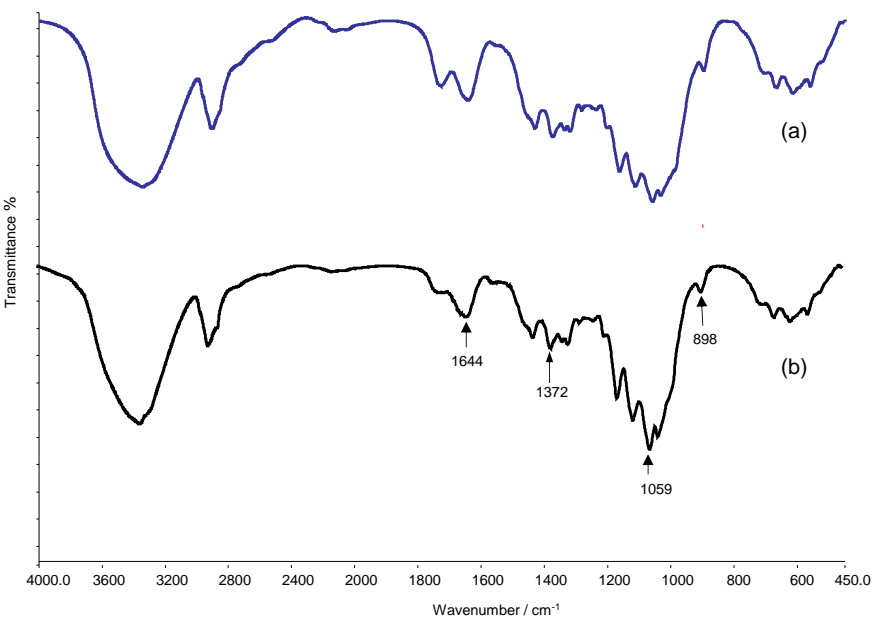

Fig. 2 FTIR spectra of (a) MCC-PELLS and (b) MCC-OELLS.

X-ray diffraction patterns of cellulose samples prepared from two different sources of waste seeds Leucaena leucocephala (OELLS and PELLS) gave similar diffraction patterns with slight difference in intensity peaks, indicating the minor changes in amorphous and crystalline regions. As shown in Table 2, the crystallinity of MCC prepared from Leucaena leucocephala waste seeds from OELSS and PELLS showed no significant difference ( $p>0.05$ ). In addition, MCC produced in this study showed higher and comparable crystallinity to those reported for corn stalks, rice straw, wheat straw and dhaincha (Nuruddin et al., 2011), cotton linter, wood pulp or flax (Lenihan et al., 2010) and MCC from kenaf core (Wang et al., 2010). The types of waste, in this case, showed no significant effect on the crystallinity of the prepared MCC.

Table 2 Crystallinity index of the MCC.

\begin{tabular}{cc}
\hline Fiber & Crystallinity Index (\%) \\
OELLS & $64.67 \pm 4.93^{\mathrm{a}}$ \\
PELLS & $59.33 \pm 3.25^{\mathrm{a}}$
\end{tabular}

Values were expressed $\pm S D$ as mean $(n=3)$. Mean within a column with different letters were significantly different $(p<0.05$, $t$-test).

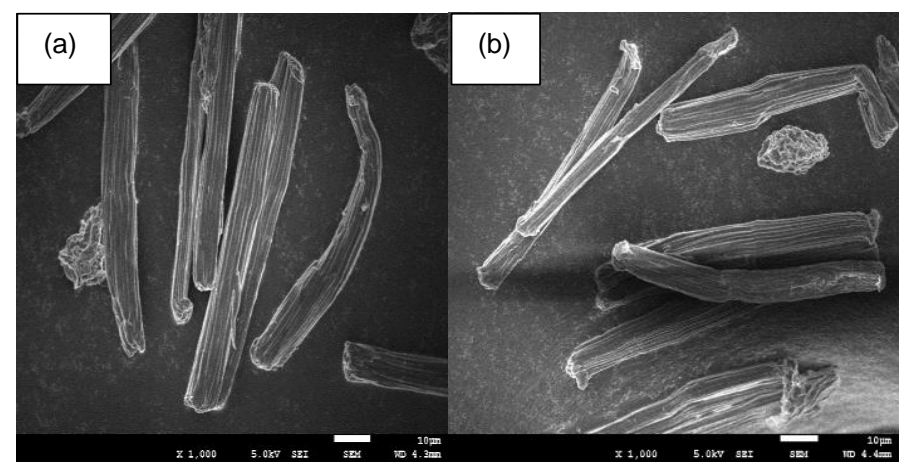

Fig. 3 FESEM images of (a) MCC-PELLS, (b) MCC- OELLS.

FESEM micrographs in Fig. 3 depicted the morphology of the different MCC samples. Generally, the obtained MCC showed rodshaped and irregular fiber fragments (Trache et al., 2014; Wang et al., 2010). The individual MCC samples that measured by FESEM images exhibited variable diameters. The diameters of MCC-PELLS and MCC-OELLS were $7.13 \pm 0.4313$ and $8.975 \pm 1.414 \mu \mathrm{m}$. The fiber diameter would affect the aspect ratio of the fiber $(\mathrm{L} / \mathrm{d})$. The difference in size of MCC was associated with its binding material such as lignin and hemicellulose in both LLS wastes (Chirayil et al., 2014; Johar et al. 2012). 


\section{Evaluation of glucose produced from prepared cellulose}

Acid hydrolysis was the most favorable way to synthesize sugars from lignocellulosic biomass which consisted of polysaccharides, cellulose and hemicellulose (Sun et al., 2015). Cellulose was made up of hexosans, therefore, it was apparent that a high yield of glucose could be derived from acid hydrolysis. Fig. 4 shows the retention time (min) of glucose by HPLC for MCC-PELLS and MCC-OELLS, where it could be confirmed that glucose was largely presented in the hydrolyzed product (sugar).

In addition, the effects of acid sulphuric concentration and reaction time on the glucose yield of both Leucaena leucocephala seed wastes were studied at $121{ }^{\circ} \mathrm{C}$. The color of hydrolyzate products from sulphuric acid hydrolysis was varied from light to dark yellow as the acid concentration was increased, suggesting the presence of byproducts. It was found that the percentage of glucose in the total sugar yield could be varied largely on the acid concentration.

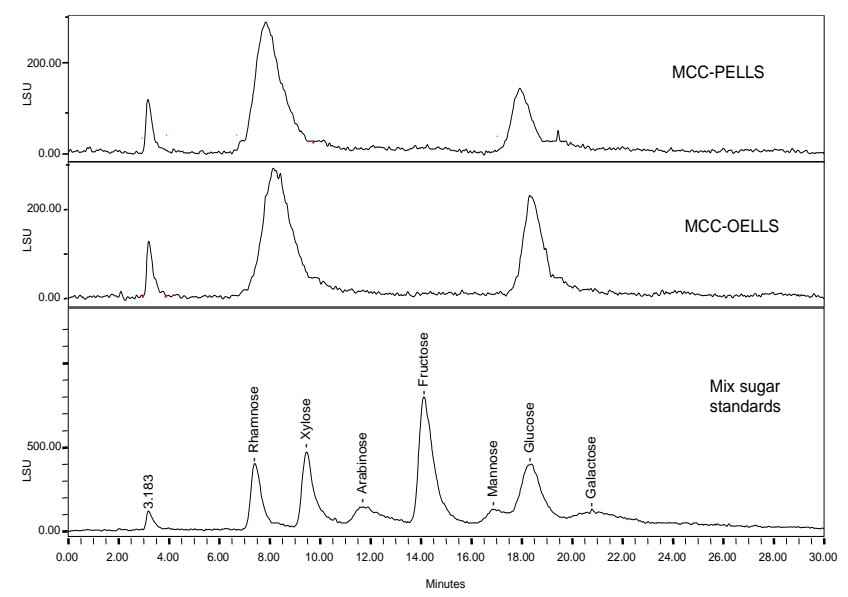

Fig. 4 HPLC chromatograms of MCC-PELLS and MCC-OELLS hydrolyzates in comparison with mix sugar standards.

In Fig. 5, treatment using acid concentration of $5 \% \mathrm{v} / \mathrm{v}$ was found to show a higher percentage of glucose at $71 \%$ for MCC-PELLS and $70 \%$ for MCC-OELLS hydrolyzate. Hutomo et al. (2015) compared the cellulose hydrolysis to glucose yield using two different acids. Based on their study, sulphuric acid gave higher glucose yield in comparison to hydrochloric acid. In another study, Wijaya et al. (2014) evaluated the effect of crystallinity on cellulose degradation of different categories of biomass (hardwood, softwood, and non-woody biomass). They reported that the lowest crystallinity gave the highest glucose yield.

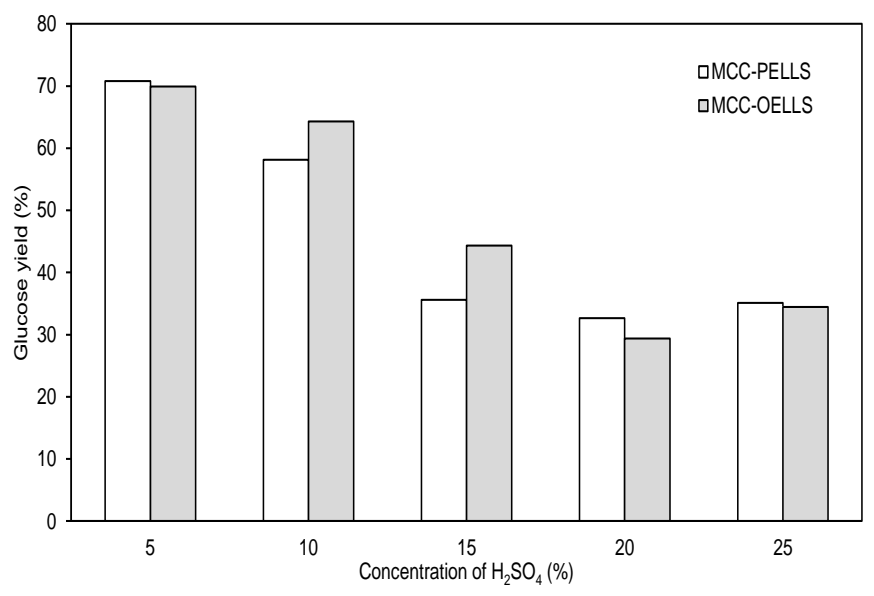

Fig. 5 Effect of different concentrations of $\mathrm{H}_{2} \mathrm{SO}_{4}$ on the yield of glucose at 60 minutes.

In total, $58 \%$ of MCC was found to be converted to glucose. Das, et al. (2016) reported that the highest yield of glucose $(60 \%)$ from cellulose rice husk was obtained in the presence of $\mathrm{H}_{2} \mathrm{SO}_{4}(5 \% \mathrm{v} / \mathrm{v})$, at $140^{\circ} \mathrm{C}$ for $60 \mathrm{~min}$. Sasaki et al. (2012) reported that the highest yield of glucose $(63.1 \%)$ from microcrystalline cellulose powder was obtained at a steam pressure of $62 \mathrm{~atm}$ for the steaming time of $1 \mathrm{~min}$. However, as the acid concentration was increased, further enhancement of in glucose formation could not be observed. This was probably due to the inevitable side reaction in glucose degradation. This data was consistent with the results obtained by Ni et al. (2013) and Sun et al. (2015). This might be explained by the greater presence of acid, where some portions of sugars were further transformed into furans (furfural and HMF) and other by-products, which leading to the loss of sugars. In the fermentation process, the HMF was an undesired component and would affect the yield of biofuel. HMF could inhibit yeast and other microorganisms used during the fermentation stage. However, HMF was also a beneficial renewable feedstock that could be converted into 2,5-dimethylfuran (Li et al., 2009).

Residence time and temperature were significantly influenced by the hydrolysis of cellulose to sugars (Dussán et al., 2014). This was due to the rigid crystalline structure of cellulose, making it was difficult to be destroyed. Therefore, the effect of reaction time on glucose yield was investigated by varying the hydrolysis time from $30 \mathrm{~min}$ to 120 min at a constant sulphuric acid concentration (5\%). Fig. 6 shows the reaction time of $120 \mathrm{~min}$ for selected acid concentrations gave significant effect to the yield of glucose. It could be suggested that the heating or reaction time showed significant influence on the hydrolysis of cellulose. This trend was in agreement with the results obtained by Morales-delaRosa et al. (2012) in the hydrolysis of cellulose using ionic liquid. However, Lanzafame et al. (2012) utilized acid catalysts in their study, showed an increment in hydrolysis productivity, although with low selectivity to glucose, due to the secondary reactions of glucose conversion.

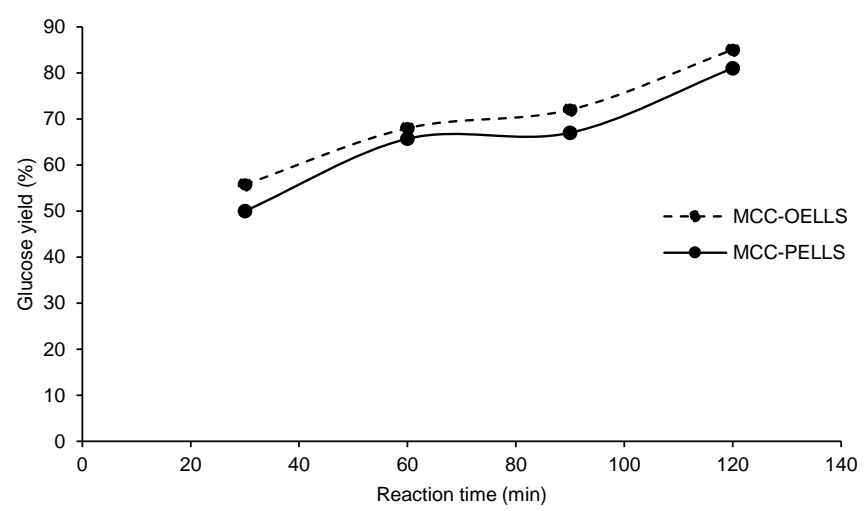

Fig. 6 Effect of reaction time on the yield of glucose.

For both conditions, MCC-OELLS gave a higher yield of glucose (around $82 \%$ ) but it was not a far difference to the glucose yield by MCC-PELLS (84\%). Given that, cellulose conversion was increased for both samples at around $71 \%$ to $75 \%$. This might be explained by the fact that the crystallinity indexes of both samples were almost similar. Besides the crystalline region, cellulose was also contained with bundles of amorphous regions, which could influence sugar yield. This was supported by Zhao et al. (2005) in their study, showing easier hydrolysis of noncrystalline (amorphous) than the crystalline fraction of cellulose. Ni et al. (2013) also reported that lower sugar yield was contributed to the higher crystallinity of cellulose. Phaiboonsilpa \& Saka (2011) also reported that Japanese cedar (Cryptomeria japonica) was liquefied by semi-flow hot-compressed water at $230^{\circ} \mathrm{C} / 10 \mathrm{MPa}$ for $15 \mathrm{~min}$ and $280^{\circ} \mathrm{C} / 10 \mathrm{MPa}$ for $30 \mathrm{~min}$ in the first and second stages, respectively, where $87.76 \%$ of the sample was converted to various compounds in the water-soluble portion although the rest was remained in the water-insoluble residue.

\section{CONCLUSION}

Cellulose was successfully extracted from two types of waste Leucaena leucocephala seeds. Furthermore, extracted cellulose could be used as a source for various applications. Cellulose could be produced from different kinds of raw material. The most important 
factor to be considered was the availability of raw materials for the targeted production. The results from this study demonstrated that acid concentration has a profound influence on glucose production. The main sugar product from hydrolyzates was glucose, indicating that pretreatment was not required for the production of glucose from waste seed evaluation. $5 \%$ of acid concentration $\left(\mathrm{H}_{2} \mathrm{SO}_{4}\right)$ with a heating rate of $2 \mathrm{~h}$ at $121{ }^{\circ} \mathrm{C}$ gave the favorable reaction conditions for the conversion of cellulose to glucose from Leucaena leucocephala seed waste. This study suggested that the use of waste of Leucaena leucocephala seeds might be a feasible option as a feed material for the production of cellulose and sugars for bioethanol and other value-added chemicals, due its low cost and high sugar yields.

\section{ACKNOWLEDGMENT}

The authors would like to thank the University of Malaya and Sustainability Science Research Cluster for continuous support and the research funding RP004B-13BIO and PG101-2015A.

\section{REFERENCES}

Adel, A. M., Abd El-Wahab, Z. H., Ibrahim, A. A., \& Al-Shemy, M. T. (2011). Characterization of microcrystalline cellulose prepared from lignocellulosic materials. Part II: Physicochemical properties. Carbohydrate Polymers, 83(2), 676-687.

Aderibigbe, S. A., Adetunji, O. ., \& Odeniyi, M. A. (2011) Antimicrobial and pharmaceutical properties of the seed oil of Leucaena leucocephala (Lam.) de Wit (Leguminosae). African Journal of Biomedical Research, 14, 63-68.

Amiri, H., \& Karimi, K. (2013). Efficient dilute-acid hydrolysis of cellulose using solvent pretreatment. Industrial and Engineering Chemistry Research, 52(33), 11494-11501.

Bentivoglio, G., Röder, T., Fasching, M., Buchberger, M., Schottenberger, H., \& Sixta, H. (2006). Cellulose processing with chloride-based ionic liquids. Lenzinger Berichte, 86, 154-161.

Cardenas-toro, F. P., Alcazar-alay, S. C., Forster-carneiro, T., \& Meireles, M. A. A. (2014). Obtaining oligo- and monosaccharides from agroindustrial and agricultural residues using hydrothermal treatments. Food and Public Health, 4(3), 123-139.

Kumar, C. S., \& Venkatesh, R. (2014). Estimation of reducing sugar by acid hydrolysis of black grape (Vitis vinifera L.) peels by standard methods. Journal of Chemical and Pharmaceutical Research, 6(5), 862-866.

Chirayil, C. J., Joy, J., Mathew, L., Mozetic, M., Koetz, J., \& Thomas, S. (2014). Isolation and characterization of cellulose nanofibrils from Helicteres isora plant. Industrial Crops and Products, 59, 27 34.

Das, A. M., Hazarika, M. P., Goswami, M., Yadav, A., \& Khound, P. (2016). Extraction of cellulose from agricultural waste using Montmorillonite $\mathrm{K}-10 / \mathrm{LiOH}$ and its conversion to renewable energy: Biofuel by using Myrothecium gramineum. Carbohydrate Polymers, 141, 20-27.

Dubois, M., Gilles, K., Hamilton, J., Rebers, P., \& Smith, F. (1956). Colorimetric method for determination of sugars and related substances. Analytical Chemistry, 28(3), 350-356.

Duff, S. J. B., \& Murray, W. D. (1996). Bioconversion of forest products industry waste cellulosics to fuel ethanol: A review. Bioresource Technology, 55, 1-33.

Dussán, K. J., Silva, D. D. V, Moraes, E. J. C., Priscila, V., \& Felipe, M. G. A. (2014). Dilute-acid hydrolysis of cellulose to glucose from sugarcane bagasse. Chemical Engineering Transactions, 38, 433438.

Gámez, S., González-Cabriales, J. J., Ramírez, J. A., Garrote, G., \& Vázquez, M. (2006). Study of the hydrolysis of sugar cane bagasse using phosphoric acid. Journal of Food Engineering, 74(1), 78-88.

Hakimi, M. I., Goembira, F., \& Ilham, Z. (2017). Engine-Compatible Biodiesel from Leucaena leucocephala Seed Oil. Journal of the Society of Automotive Engineers Malaysia, 1(2), 86-93.

Hsu, W., Lee, Y., Peng, W., \& Wu, K. C. (2011). Cellulosic conversion in ionic liquids ( ILs ): Effects of $\mathrm{H}^{2} \mathrm{O} /$ cellulose molar ratios , temperatures, times, and different ILs on the production of monosaccharides and 5-hydroxymethylfurfural (HMF). Catalysis Today, 174(1), 65-69.

Hutomo, G. S., Rahim, A., \& Kadir, S. (2015). The effect of sulfuric and hydrochloric acid on cellulose degradation from pod husk cacao. International Journal on Current Microbiology and Applied Sciences, 4(10), 89-95.

Iryani, D. A., Kumagai, S., Nonaka, M., Nagashima, Y., Sasaki, K., \& Hirajima, T. (2014). The hot compressed water treatment of solid waste material from the sugar industry for valuable chemical production. International Journal of Green Energy, 11 (November), 577-588.

Johar, N., Ahmad, I., \& Dufresne, A. (2012). Extraction, preparation and characterization of cellulose fibres and nanocrystals from rice husk. Industrial Crops and Products, 37(1), 93-99.

Jose, C., Joy, J., Mathew, L., Koetz, J., \& Thomas, S. (2014). Nanofibril reinforced unsaturated polyester nanocomposites: Morphology, mechanical and barrier properties, viscoelastic behavior and polymer chain confinement. Industrial Crops \& Products, 56, 246254.

Kalia, S., Dufresne, A., Cherian, B. M., Kaith, B. S., Av, L., Njuguna, J., \& Nassiopoulos, E. (2011). Cellulose-based bio- and nanocomposites: A review. International Journal of Polymer Science, 2011, 1-35.

Kamio, E., Takahashi, S., Noda, H., Fukuhara, C., \& Okamura, T. (2008). Effect of heating rate on liquefaction of cellulose by hot compressed water. Chemical Engineering Journal, 137, 328-338.

Kopania, E., Wietecha, J., \& Ciechańska, D. (2012). Studies on isolation of cellulose fibres from waste plant biomass. Fibres and Textiles in Eastern Europe, 96(6 B), 167-172.

Kumar, S., Dheeran, P., Singh, S. P., Mishra, I. M., \& Adhikari, D. K. (2015). Kinetic studies of two-stage sulphuric acid hydrolysis of sugarcane bagasse. Renewable Energy, 83, 850-858.

Lanzafame, P., Temi, D. M., Perathoner, S., Spadaro, A. N., \& Centi, G. (2012). Direct conversion of cellulose to glucose and valuable intermediates in mild reaction conditions over solid acid catalysts. Catalysis Today, 179(1), 178-184.

Lee, J. (1997). Biological conversion of lignocellulosic biomass to ethanol. Journal of Biotechnology, 56(1), 1-24.

Lenihan, P., Orozco, A., O’Neill, E., Ahmad, M. N. M., Rooney, D. W., \& Walker, G. M. (2010). Dilute acid hydrolysis of lignocellulosic biomass. Chemical Engineering Journal, 156, 395403.

Li, C., Zhang, Z., \& Zhao, Z. K. (2009). Direct conversion of glucose and cellulose to 5-hydroxymethylfurfural in ionic liquid under microwave irradiation. Tetrahedron Letters, 50(38), 5403-5405.

Li, F. H., Hu, H. J., Yao, R. S., Wang, H., \& Li, M. M. (2012). Structure and saccharification of rice straw pretreated with microwaveassisted dilute lye. Industrial and Engineering Chemistry Research, $51,6270-6274$.

Liu, Z., Li, L., Liu, C., \& Xu, A. (2017). Sacchari fi cation of cellulose in the ionic liquids and glucose recovery. Renewable Energy, 106, 99-102.

Mandal, A., \& Chakrabarty, D. (2011). Isolation of nanocellulose from waste sugarcane bagasse (SCB) and its characterization. Carbohydrate Polymers, 86(3), 1291-1299.

Morales-delaRosa, S., Campos-Martin, J. M., \& Fierro, J. L. G. (2012). High glucose yields from the hydrolysis of cellulose dissolved in ionic liquids. Chemical Engineering Journal, 181-182, 538-541.

Nehdi, I. A., Sbihi, H., Tan, C. P., \& Al-Resayes, S. I. (2014). Leucaena leucocephala (Lam.) de Wit seed oil: Characterization and uses. Industrial Crops and Products, 52, 582-587.

Ni, J., Wang, H., Chen, Y., She, Z., Na, H., \& Zhu, J. (2013). A novel facile two-step method for producing glucose from cellulose. Bioresource Technology, 137, 106-110.

Nuruddin, M., Chowdhury, A., Haque, S. A., Rahman, M., Farhad, S. F., Jahan, M. S., \& Quaiyyum, A. (2011). Extraction and characterization of cellulose microfibrils from agricultural wastes in an integrated biorefinery initiative. Cellulose Chemistry and Technology., 45(5-6), 347-354.

Orozco, A., Ahmad, M., Rooney, D., \& Walker, G. (2007). Dilute acid hydrolysis of cellulose and cellulosic bio-waste using a microwave 
reactor system. Process Safety and Environmental Protection, 85, 446-449.

Parawira, W. (2010). Biodiesel production from Jatropha curcas: A review. Scientific Research and Essays, 5(14), 1796-1808.

Phaiboonsilpa, N., \& Saka, S. (2011). Two-step hydrolysis of Japanese cedar as treated by semi-flow hot-compressed water with acetic acid. Green Energy and Technology, 66(December 2017), 142146.

Phaiboonsilpa, N., Tamunaidu, P., \& Saka, S. (2011). Two-step hydrolysis of nipa (Nypa fruticans) frond as treated by semi-flow hot-compressed water. Holzforschung, 65(5), 659-666.

Pius, A., Ekebafe, L., Ugbesia, S., \& Pius, R. (2014). Modification of adhesive using cellulose micro-fiber ( $\mathrm{CMF}$ ) from melon seed shell. American Journal of Polymer Science, 4(4), 101-106.

Poletto, M., Júnior, H., \& Zattera, A. (2014). Native cellulose: structure, characterization and thermal properties. Materials, 7(9), $6105-6119$

Punsuvon, V., Vaithanomsat, P., \& Iiyama, K. (2008). Simultaneous production of $\alpha$-cellulose and furfural from bagasse by steam explosion pretreatment. Maejo International Journal of Science and Technology, 2(1), 182-191.

Sasaki, C., Sumimoto, K., Asada, C., \& Nakamura, Y. (2012). Direct hydrolysis of cellulose to glucose using ultra-high temperature and pressure steam explosion. Carbohydrate Polymers, 89(1), 298301.

Siqueira, G., Várnai, A., Ferraz, A., \& Milagres, A. M. F. (2013). Enhancement of cellulose hydrolysis in sugarcane bagasse by the selective removal of lignin with sodium chlorite. Applied Energy, 102, 399-402.

Sun, B., Peng, G., Duan, L., Xu, A., \& Li, X. (2015). Pretreatment by $\mathrm{NaOH}$ swelling and then $\mathrm{HCl}$ regeneration to enhance the acid hydrolysis of cellulose to glucose. Bioresource Technology, 196, 454-458.

Sun, J. X., Sun, X. F., Zhao, H., \& Sun, R. C. (2004). Isolation and characterization of cellulose from sugarcane bagasse. Polymer Degradation and Stability, 84(2), 331-339.

Sun, N., Liu, H., Sathitsuksanoh, N., Stavila, V., Sawant, M., Bonito, A., Holmes, B. M. (2013). Production and extraction of sugars from switchgrass hydrolyzed in ionic liquids. Biotechnology for Biofuels, 6(1), 39.

Szczodrak, J., \& Fiedurek, J. (1996). Technology for conversion of lignocellulosic biomass to ethanol. Biomass and Bioenergy, 10(56), 367-375.

Taherzadeh, M. J., Eklund, R., Gustafsson, L., Niklasson, C., \& Lidén, G. (1997). Characterization and fermentation of dilute-acid hydrolyzates from wood. Industrial \& Engineering Chemistry Research, 36(11), 4659-4665.

Trache, D., Donnot, A., Khimeche, K., Benelmir, R., \& Brosse, N. (2014). Physico-chemical properties and thermal stability of microcrystalline cellulose isolated from Alfa fibres. Carbohydrate Polymers, 104(1), 223-230.

Vala, R. M. K., \& Tichagwa, L. (2013). Cellulose chemistry and technology low temperature acid hydrolysis of grass-derived lignocellulose for fermentable sugars production. Cellulose Chemistry and Technology, 47, 565-572.

Wang, D., Shang, S. Bin, Song, Z. Q., \& Lee, M. K. (2010). Evaluation of microcrystalline cellulose prepared from kenaf fibers. Journal of Industrial and Engineering Chemistry, 16(1), 152-156.

Wijaya, Y. P., Putra, R. D. D., Widyaya, V. T., Ha, J. M., Suh, D. J., \& Kim, C. S. (2014). Comparative study on two-step concentrated acid hydrolysis for the extraction of sugars from lignocellulosic biomass. Bioresource Technology, 164, 221-231.

Yoon, S. Y., Han, S. H., \& Shin, S. J. (2014). The effect of hemicelluloses and lignin on acid hydrolysis of cellulose. Energy, 77, 19-24.

Zhao, H., Kwak, J. H., Wang, Y., Franz, J. A., White, J. M., \& Holladay, J. E. (2005). Effects of crystallinity on dilute acid hydrolysis of cellulose by cellulose ball-milling. Energy Fuels, 20(2), 807-811.

Zhu, S., Wu, Y., Yu, Z., Liao, J., \& Zhang, Y. (2005). Pretreatment by microwave/alkali of rice straw and its enzymic hydrolysis. Process Biochemistry, 40, 3082-3086.

Zhuo, K., Du, Q., Bai, G., Wang, C., Chen, Y., \& Wang, J. (2015). Hydrolysis of cellulose catalyzed by novel acidic ionic liquids. Carbohydrate Polymers, 115, 49-53. 